\title{
Caracterização sensorial de cookies de amora
}

Michele Rosset, Márcia Arocha Gularte

https://doi.org/10.4322/mp.978-65-991393-5-2.c1

\section{Resumo}

O objetivo deste trabalho foi desenvolver formulações de biscoitos tipo cookies, adicionadas de polpa de amora, e caracterizá-las quanto à diferença, preferência, aceitabilidade sensorial e intenção de compra. Foram desenvolvidas duas formulações de cookies, com $7 \%$ e $12 \%$ de polpa de amora. Para análise de diferença e preferência sensorial foram utilizados os testes Triangular e Pareado de Preferência, respectivamente. A aceitação dos cookies foi verificada mediante teste de escala hedônica, avaliando-se a aceitação global. Avaliou-se a intenção de compra dos consumidores em relação ao produto por meio de escala de atitude de compra. Além disso, foram avaliados os parâmetros colorimétricos dos cookies, antes e após o forneamento. Com relação à cor dos cookies, houve diferença entre as amostras nos parâmetros $L^{*}, a^{*}$ e $b^{*}$, antes e após a cocção $(P<0,05)$. $O$ teste triangular indicou que as amostras diferiram entre si $(P<0,05)$. No teste pareado de preferência, os avaliadores preferiram a amostra com $12 \%$ de polpa de amora. Os índices de aceitabilidade foram superiores a $70 \%$, indicando boa aceitação das formulações. Quanto à intenção de compra foi observado que a maioria dos avaliadores certamente compraria os biscoitos, de ambas as formulações.

Palavras-chave: análise sensorial, cor, índice de aceitabilidade, intenção de compra.

\section{Introdução}

A amoreira-preta (Rubus sp.) é uma espécie arbustiva de porte ereto ou rasteiro, que produz frutos agregados com cerca de quatro a sete gramas, de coloração preta e gosto ácido a doce-ácido. É uma planta rústica que apresenta baixo custo de produção, facilidade de manejo, requer pouca utilização de defensivos agrícolas e, por isso, é uma alternativa interessante para cultivo na agricultura familiar (MOTA, 2006). Os Estados Unidos lideram a produção mundial de amora-preta com 11.905 hectares de área plantada e produção de 35.099 toneladas, seguido pelo Chile com 1.111 hectares e produção de 4.275 toneladas (TULLIO; AYUBI, 2013).

No ano de 2005, segundo Strik et al. (2007), a área plantada com amora-preta no Brasil era de 250 hectares, sendo que, nos últimos anos, a mesma aumentou cerca de $100 \%$, chegando a aproximadamente 500 hectares. Os principais Estados produtores estão localizados nas regiões Sul e Sudeste, sendo eles, Rio Grande do Sul (principal produtor), Santa Catarina, Paraná, Minas Gerais, São Paulo e Espírito Santo (ANTUNES et al., 2014; TULLIO; AYUBI, 2013; ANTUNES, 2002).

A amora-preta in natura é altamente nutritiva, contendo $85 \%$ de água, $10 \%$ de carboidratos, elevado conteúdo de minerais, vitaminas do complexo $B$, vitamina $A$ e 
cálcio. Outra característica interessante é a possibilidade de comercialização, pois trata-se de uma fruta que possibilita a elaboração de uma grande variedade de produtos, tais como iogurtes, geleias, doces e sucos, além de ser comercializada in natura (ANTUNES et al., 2014; JACQUES; SAMBIAZI, 2011).

Devido ao elevado teor de umidade, a amora-preta apresenta-se como um fruto de difícil conservação na forma in natura e, por esse motivo, é normalmente destinada à produção de polpa, a qual pode ser utilizada no desenvolvimento de outros produtos, como por exemplo biscoitos.

O Brasil é o $2^{\circ}$ maior produtor mundial de biscoitos. Em 2019 a produção foi de 1,47 milhões de toneladas. Em termos de faturamento, o setor cresceu 1,7\% em relação ao ano de 2018 (NEWTRADE, 2020). Há diversas pesquisas que tratam do desenvolvimento de biscoitos tipo cookies utilizando farinhas obtidas a partir de resíduos do processamento de fruta (FASOLIN et al., 2007; SANTOS et al., 2008 e ALVES et al., 2012). No entanto, não foram encontrados trabalhos que utilizassem a polpa de amora, motivo pelo qual a pesquisa foi desenvolvida.

Para verificar as características sensoriais dos biscoitos tipo cookies são utilizadas ferramentas da análise sensorial, como testes de diferença e testes afetivos como de preferência e aceitação. De acordo com Dutcosky (2019), o teste de diferença triangular tem como objetivo verificar se existe diferença significativa entre duas amostras que sofreram tratamentos diferentes, durante o processamento, condições de estocagem, embalagem ou mudanças de ingredientes nas formulações. Consiste num teste para detectar pequenas diferenças e por este motivo é amplamente utilizado antes de outros testes, pois não avalia o grau nem caracteriza os atributos responsáveis pela diferença, ou seja, avalia o produto globalmente.

Com relação aos métodos afetivos, consistem numa importante ferramenta, pois expressam diretamente a opinião (preferência ou aceitação) do consumidor em relação às ideias, características específicas ou globais de determinado produto, sendo, por isso, também denominados testes de consumidor (DUTCOSKY, 2019).

Os testes de preferência têm como objetivo avaliar a preferência do consumidor quando ele compara dois ou mais produtos entre si, enquanto o teste de aceitabilidade tem como objetivo avaliar o grau com que consumidores gostam ou desgostam de um produto. A aceitabilidade pode ser definida como expressão do grau de gostar; uma experiência caracterizada por uma atitude positiva e pela utilização atual do produto (hábito de comprar ou consumir um alimento) (DUTCOSKY, 2019).

Considerando à boa aceitação, elevado consumo e longa vida útil, a produção de biscoitos tipo cookies se apresenta como uma alternativa diferenciada na utilização de polpa de amora. Deste modo, o objetivo desta pesquisa foi desenvolver um biscoito tipo cookie adicionado de polpa de amora e avaliar as características sensoriais quanto à diferença, preferência, aceitabilidade e intenção de compra do produto.

\section{Materiais e Métodos}

\subsection{Produção da polpa de amora-preta}

Para a produção da polpa foram utilizados frutos in natura de amora-preta, cultivar Tupy, provenientes da cidade de Jacarezinho (PR). Após a colheita manual, os frutos foram selecionados quanto à sanidade, integridade física e coloração, lavados em água corrente para remoção de sujidades e, em seguida, imersos em água clorada 
contendo 180 ppm de cloro ativo durante 10 minutos. Após enxague, os frutos foram drenados, pesados e triturados em liquidificador (Britânia, modelo diamante, $600 \mathrm{~W}$ ) por 90 segundos. O rendimento da polpa foi de $441 \mathrm{~g}$. Na sequência, a polpa foi submetida a tratamento térmico, na temperatura de $75^{\circ} \mathrm{C}$ durante 15 minutos. Após resfriamento, a polpa foi acondicionada em recipiente de vidro e armazenada em freezer doméstico $\left(-18^{\circ} \mathrm{C}\right)$.

\subsection{Produção dos biscoitos tipo cookies}

Os biscoitos tipo cookies foram elaborados no Laboratório de Alimentos do Instituto Federal do Paraná, Campus Jacarezinho-PR. Para a produção dos biscoitos, foram utilizados como ingredientes farinha de trigo, farinha de arroz, açúcar, manteiga sem sal, amido de milho e polpa de amora. Os ingredientes foram adquiridos no comércio local da cidade de Jacarezinho, Paraná.

As formulações foram desenvolvidas por meio de experimentos prévios no laboratório. Utilizou-se como base uma formulação convencional de biscoito tipo cookie, adaptada para a adição de polpa de amora. Foram preparadas diferentes formulações, variandose as proporções entre as quantidades de farinha de trigo e farinha de arroz (Tabela 1).

Tabela 1. Formulação básica dos biscoitos tipo cookies.

\begin{tabular}{cc}
\hline Ingredientes & Porcentagem $(\% \mathrm{~m} / \mathrm{m})$ \\
\hline Farinha de trigo & 39,7 \\
Farinha de arroz & 9,4 \\
Açúcar & 24,8 \\
Manteiga & 19,9 \\
Amido de milho & 6,2 \\
\hline Total & $100 \%$ \\
\hline
\end{tabular}

A partir dos pré-testes foram elaboradas 2 (duas) formulações de biscoitos tipo cookies, a formulação F1 com $7 \%$ de polpa $(32,24 \mathrm{~g})$ e a formulação $\mathrm{F} 2$ com $12 \%$ de polpa $(48,36 \mathrm{~g})$. A quantidade de polpa foi calculada a partir da quantidade total (403 g) de massa.

A massa foi processada em batedeira elétrica (Arno, modelo ciranda) por 6 minutos em velocidade média. Em seguida, a massa foi estendida e aberta com rolo de acrílico. Um molde redondo (diâmetro igual a $35 \mathrm{~mm}$ ) foi utilizado para cortar a massa no formato dos cookies, os quais foram assados, em forno pré-aquecido por 10 minutos a $240{ }^{\circ} \mathrm{C}$, durante 23 minutos. Em seguida foram resfriados à temperatura ambiente e armazenados em potes de vidro vedados até o momento das análises colorimétrica e sensorial.

\subsection{Composição centesimal dos biscoitos tipo cookies}

Teores médios de umidade, cinzas, proteínas, lipídeos e carboidratos foram calculados a partir de Gazola (2014) e Taco (2011).

\subsection{Determinação instrumental da cor}

A cor dos biscoitos foi determinada no colorímetro modelo CR-410 (Konica Minolta, Japão), usando sistema CIEL $a^{\star} b^{\star}$, no qual os valores de luminosidade ( $\left.L^{\star}\right)$ variam 
entre zero (preto) e 100 (branco), os valores das coordenadas de cromaticidade $a^{*} \mathrm{e}$ $b^{\star}$, variam de $-a^{*}$ (verde) até $+a^{*}$ (vermelho), e de $-b^{*}$ (azul) até $+b^{*}$ (amarelo). As análises foram realizadas nos biscoitos antes e após a cocção.

\subsection{Análise sensorial dos biscoitos tipo cookies}

A análise sensorial foi realizada no Laboratório de Análise Sensorial de Alimentos do Instituto Federal do Paraná, Campus Jacarezinho, PR, com participação de docentes, estudantes e funcionários não treinados. O número de avaliadores no teste triangular foi de 64 avaliadores, entre 23 a 57 anos (86\% do sexo feminino e 14\% do sexo masculino). Nos testes afetivos houve a participação de 42 avaliadores, entre 14 a 52 anos ( $55 \%$ do sexo feminino e $45 \%$ do sexo masculino).

Foram aplicados os testes de diferença triangular (Figura 1), teste pareado de preferência e teste de aceitação com escala hedônica estruturada de 9 (nove) pontos (Figura 2), sendo os extremos valor 1 equivalente ao termo hedônico "desgostei muitíssimo" e o valor 9 atribuído ao termo "gostei muitíssimo", para a avaliação global.

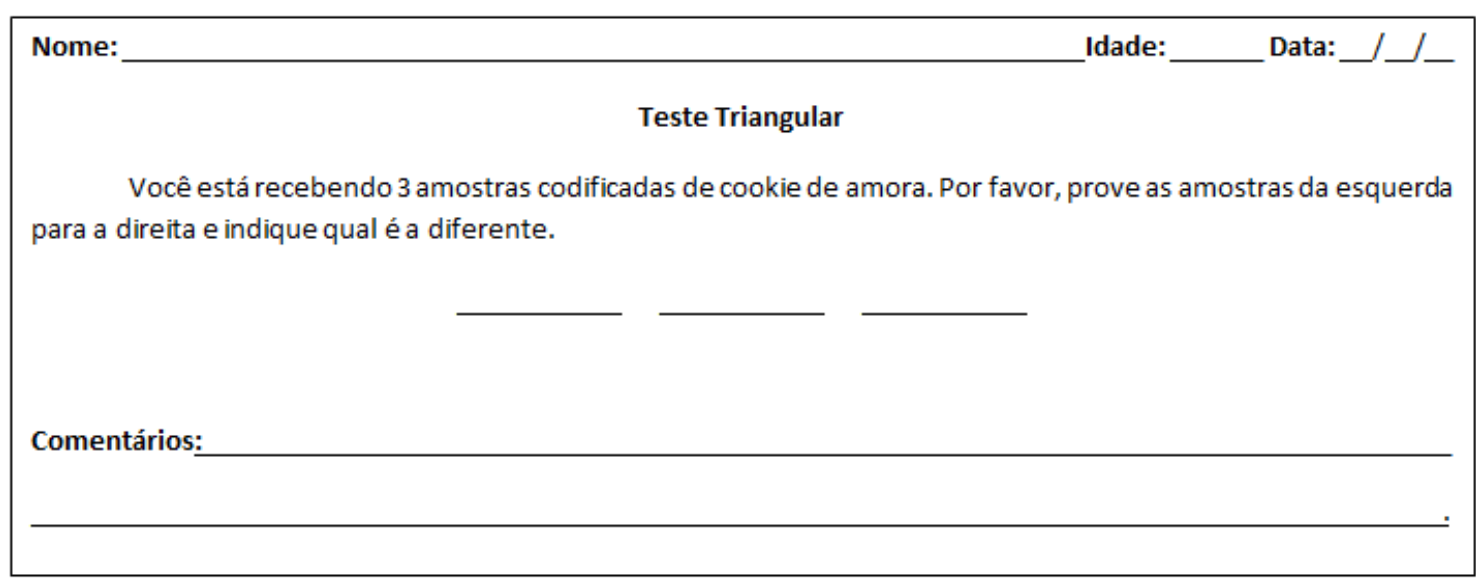

Figura 1. Ficha aplicada no teste sensorial de diferença triangular para cookies de amora.

Além disso, foi determinado o índice de aceitabilidade (IA) que relaciona a nota média do atributo avaliado com a nota mais alta da escala (TEIXEIRA; MEINERT; BARBETTA, 1987), utilizando a equação abaixo:

$$
I A=\frac{\text { nota média obtida pelo produto }}{\text { nota máxima da escala }} \times 100
$$

A intenção de compra do consumidor foi avaliada por meio de escala de 5 pontos, com variação entre "1 - certamente não compraria" e "5 - certamente compraria (Figura 2). As amostras foram servidas aos avaliadores à temperatura ambiente, em pratos descartáveis de cor branca codificados com três dígitos aleatórios, acompanhadas de um copo de água. Para o teste triangular, foram servidas três amostras, em que duas amostras eram iguais e uma diferente e então foi solicitado ao avaliador que identificasse a amostra diferente. Para os testes afetivos, foi servido um biscoito de cada formulação simultaneamente. 


\subsection{Análise estatística}

Os resultados obtidos na análise de cor e nos testes sensoriais foram analisados estatisticamente empregando o programa Statistica 7 (STATSOFT, 2007), por Análise de Variância (ANOVA) e teste de médias de ' $\mathrm{t}$ ' $(P<0,05)$. Os resultados do teste pareado de preferência foram analisados por meio da tabela de comparação pareada bicaudal. A análise estatística do teste triangular se baseou no número de acertos. $O$ número de respostas corretas necessárias para estabelecer diferenças significativas é encontrado na Tabela de O'Mahony (1986), com probabilidade de acerto ao acaso de $1 / 3$.

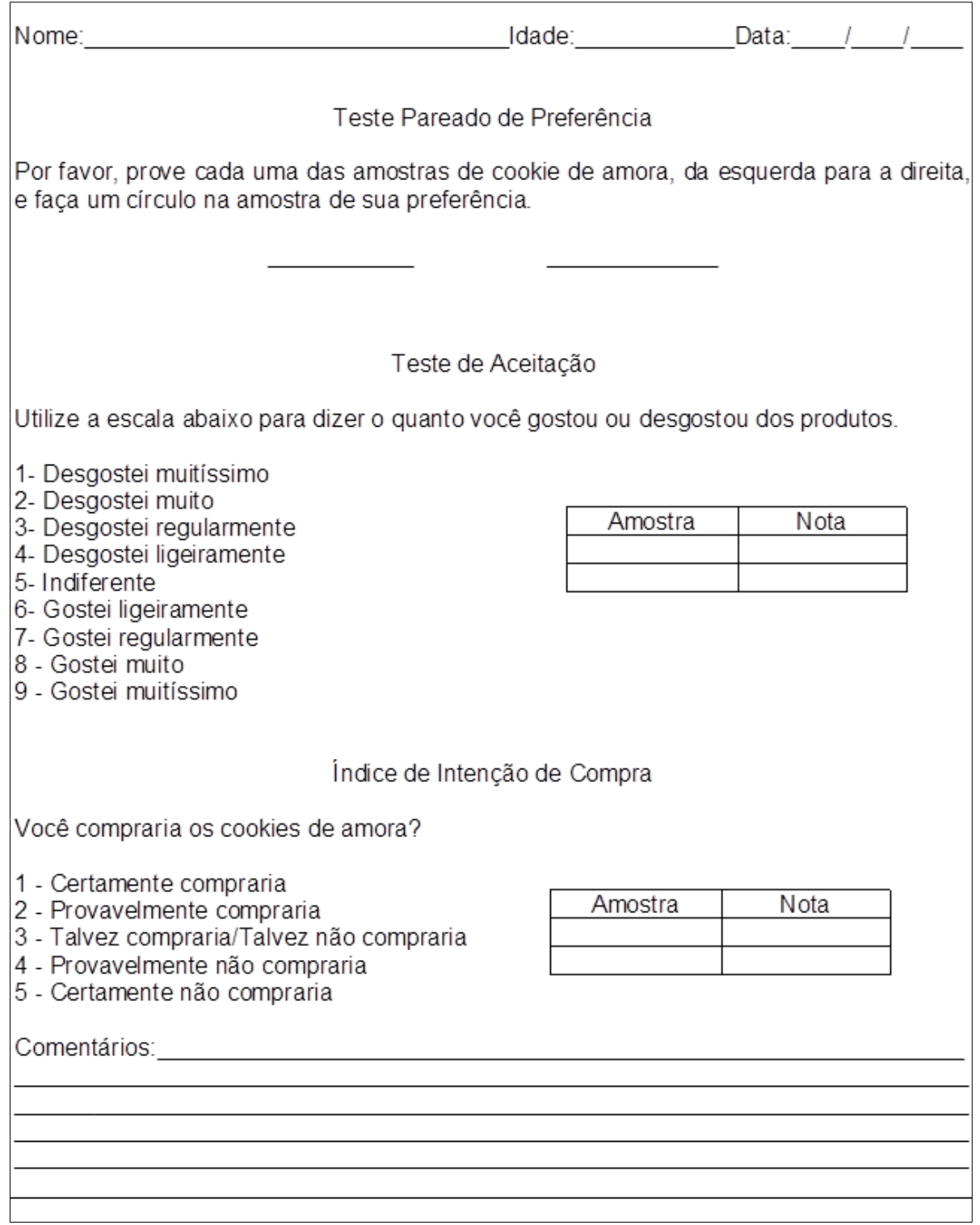

Figura 2. Ficha sensorial aplicada nos testes afetivos e intenção de compra.

\section{Resultados e Discussão}

Gazola (2014) caracterizou físico-quimicamente polpa de frutas, incluindo polpa de amora. Os teores de umidade, proteínas, lipídeos, cinzas e carboidratos de polpa de 
amora foram 90,21\%, 1,10\%, 0,47\%, 0,95\% e 7,28\%, respectivamente. Chim (2008) caracterizou três cultivares de amora, conforme a Tabela 2.

Devido ao elevado teor de umidade, a amora-preta apresenta-se como um fruto de difícil conservação na forma in natura, por esse motivo é normalmente destinada à produção de polpa. Imran et al. (2010) reportaram valores de $82,40 \%, 0,96 \%, 0,50 \%$, $0,55 \%$ e $13,83 \%$ para umidade, proteínas, cinzas, lipídeos e carboidratos totais, respectivamente.

A partir dos valores obtidos por Gazola (2014) de umidade, cinzas, lipídeos, carboidratos e proteínas e dos valores de referência da Tabela Brasileira de Composição de Alimentos (TACO, 2011), foi possível calcular os valores médios da composição centesimal dos biscoitos tipo cookies de amora (Tabela 3).

Tabela 2. Caracterização físico-química de cultivares de amora.

\begin{tabular}{lccc} 
& Análises & \multicolumn{2}{c}{ Cultivares } \\
& Guarani & Tupy & Brazos \\
\hline Umidade (\%) & 87 & 88 & 89 \\
Proteína (\%) & 0,75 & 0,83 & 1,24 \\
Cinzas (\%) & 0,86 & 0,40 & 0,89 \\
Fibra (\%) & 2,02 & 2,52 & 2,05 \\
Lipídeos (\%) & 0,17 & 0,15 & 0,14 \\
Acidez (\% em ácido málico) & 1,33 & 0,95 & 1,16 \\
Sólidos solúveis (\% Brix) & 8,5 & 8,5 & 8,6 \\
Açúcares totais (\% em glicose) & 7,10 & 6,96 & 4,09 \\
Açúcares redutores (\% em glicose) & 6,93 & 6,69 & 4,03 \\
Açúcares não-redutores (\% em sacarose) & 0,17 & 0,27 & 0,06 \\
\hline
\end{tabular}

Fonte: Chim (2008).

Tabela 3. Composição centesimal dos cookies de amora.

\begin{tabular}{lcc}
\hline Análises (\%)* & Formulação F1 & Formulação F2 \\
\hline Umidade & 15,47 & 18,69 \\
Proteína & 4,00 & 3,83 \\
Cinzas & 0,40 & 0,42 \\
Lipídeos & 16,06 & 16,05 \\
Carboidratos & 64,13 & 61,06 \\
\hline Valor calórico (porção de 100 g) & 417,06 kCal & 404,01 kCal \\
\hline * Valores médios calculados a partir de Gazola (2014) e TACO (2011). F1: Biscoito tipo cookie \\
formulado com 7\% de polpa de amora. F2: Biscoito tipo cookie formulado com 12\% de polpa de \\
amora.
\end{tabular}


A cor dos biscoitos pode ser influenciada pelos ingredientes utilizados na formulação, como o teor de açúcar, o tempo e a temperatura de forneamento, promovendo as reações de escurecimento caramelização e Maillard. No presente trabalho foi possível observar que houve diferença entre as amostras em todos os parâmetros de cor, antes e após forneamento (Tabela 4).

Tabela 4. Parâmetros de cor dos biscoitos tipo cookies de amora**.

\begin{tabular}{cccc}
\hline & $\begin{array}{c}\text { Parâmetro } \\
\text { colorimétrico }\end{array}$ & Formulação F1 & Formulação F2 \\
\hline $\begin{array}{c}\text { Antes do } \\
\text { forneamento }\end{array}$ & $\mathrm{L}$ & $47,32 \pm 1,07^{\mathrm{a}}$ & $38,94 \pm 0,53^{\mathrm{b}}$ \\
& $\mathrm{a}^{\star}$ & $16,99 \pm 0,40^{\mathrm{b}}$ & $18,58 \pm 0,50^{\mathrm{a}}$ \\
& $\mathrm{b}^{*}$ & $5,25 \pm 0,23^{\mathrm{a}}$ & $1,87 \pm 0,09^{\mathrm{b}}$ \\
\hline \multirow{2}{*}{ Após } & $\mathrm{L}$ & $52,98 \pm 1,81^{\mathrm{a}}$ & $46,86 \pm 0,8^{\mathrm{b}}$ \\
forneamento & $\mathrm{a}^{\star}$ & $12,93 \pm 0,5^{\mathrm{b}}$ & $15,57 \pm 0,46^{\mathrm{a}}$ \\
& $\mathrm{b}^{*}$ & $4,16 \pm 0,52^{\mathrm{a}}$ & $3,02 \pm 0,17^{\mathrm{b}}$
\end{tabular}

F1: Biscoito tipo cookie com $7 \%$ de polpa de amora. F2: Biscoito tipo cookie com $12 \%$ de polpa de amora. ${ }^{* \star}$ Médias seguidas de letras diferentes na mesma linha, diferem entre si pelo teste 't' $(P<0,05)$.

Os biscoitos tipo cookies formulados com $7 \%$ de polpa de amora apresentaram maiores valores de luminosidade (47,32 e 52,98, antes e após o forneamento,

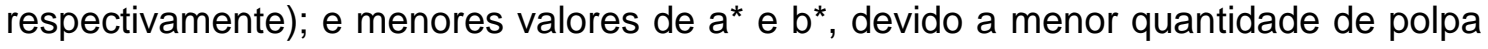
utilizada na formulação.

De acordo com a tabela de O'Mahony (1986), a qual determina o número mínimo de respostas corretas necessárias para estabelecer diferenças significativas entre duas amostras, foi observado que houve diferença entre as formulações dos biscoitos tipo cookies, com probabilidade de acerto ao acaso de 1/3 (56 avaliadores acertaram a amostra diferente). A tabela de O’Mahony (1986) indica um número de, no mínimo, 28 acertos para esta mesma quantidade de avaliadores.

No teste pareado de preferência, 33\% dos avaliadores preferiram os cookies formulados com $7 \%$ de polpa de amora, enquanto $67 \%$ preferiram os cookies formulados com $12 \%$ de polpa de amora. Deste modo, como tivemos 28 respostas positivas para o biscoito tipo cookie com $12 \%$ de polpa de amora, esta amostra foi preferida em relação ao biscoito tipo cookie com $7 \%$ de polpa de amora em nível de $5 \%$ de significância $(P<0,05)$.

Os escores médios obtidos no teste de aceitação foram de 7,57 e 7,64 para os cookies formulados com $7 \%$ e $12 \%$ de polpa de amora, respectivamente, e não apresentaram diferença entre si $(P>0,05)$. A maioria (30) dos avaliadores julgou como "gostei muito" e "gostei muitíssimo" os cookies formulados com 12\% de polpa, enquanto 24 avaliadores apontaram para "gostei regularmente e gostei muitíssimo" os cookies formulados com $7 \%$ de polpa de amora (Figura 3). Os índices de aceitabilidade (I.A.) dos biscoitos tipo cookies de amora foram de $84 \%$ e $85 \%$ para os formulados com $7 \%$ e $12 \%$ de polpa, respectivamente. De acordo com Teixeira, Meinert e Barbetta (1987), 
um produto é considerado como aceito quando o I.A. alcançar, no mínimo, 70\%. Os resultados obtidos na análise sensorial demonstram que biscoitos formulados com polpa de amora podem ser viáveis comercialmente, pois apresentaram índices de aceitação superiores a $70 \%$.

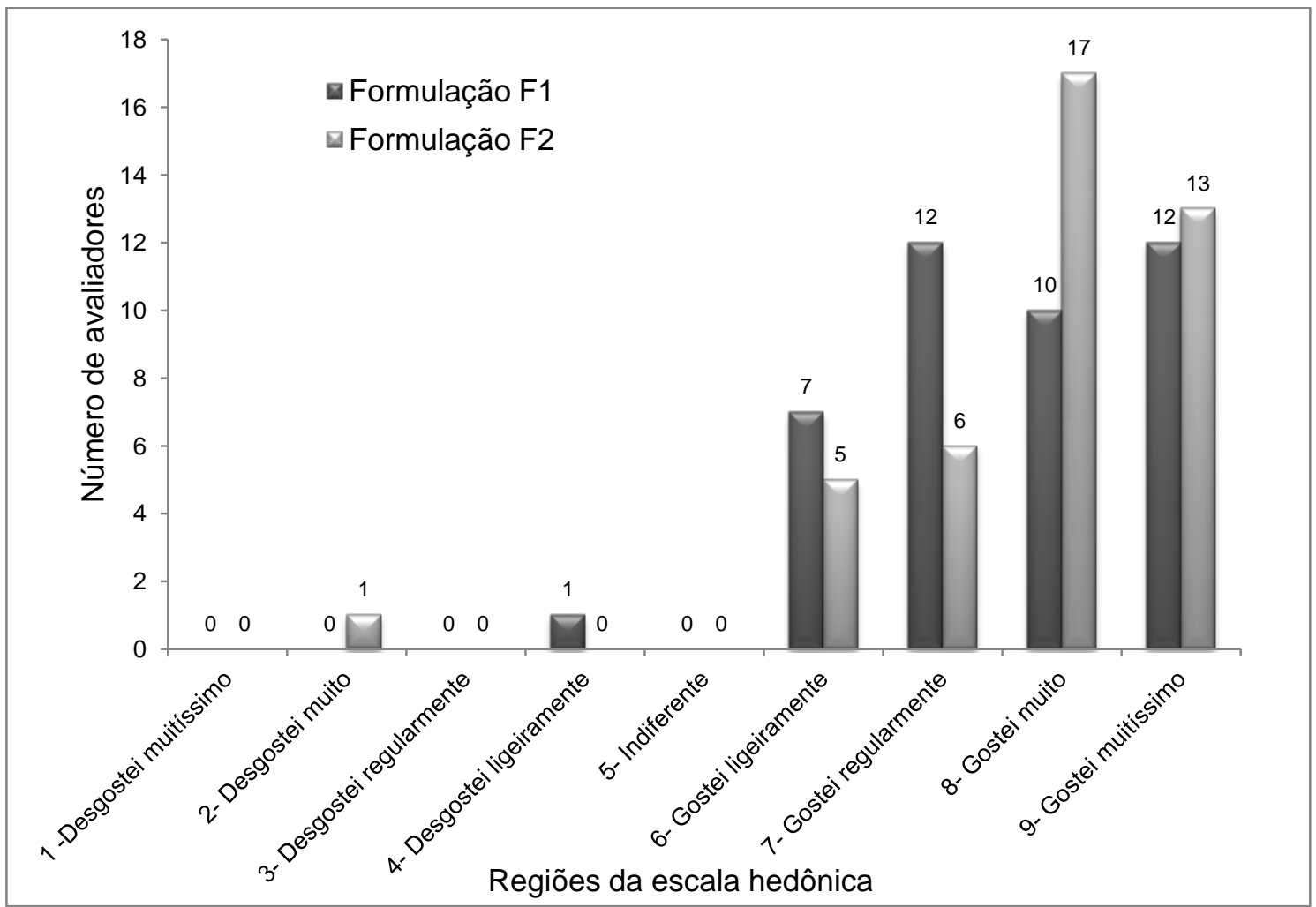

Figura 3. Teste de aceitação dos biscoitos tipo cookies de amora.

Na Figura 4 estão apresentados os resultados de intenção de compra dos avaliadores com relação aos cookies. Foi observado que a maioria dos avaliadores julgaram como "certamente compraria" os biscoitos, de ambas as formulações. Nenhum avaliador julgou com o termo "certamente não compraria".

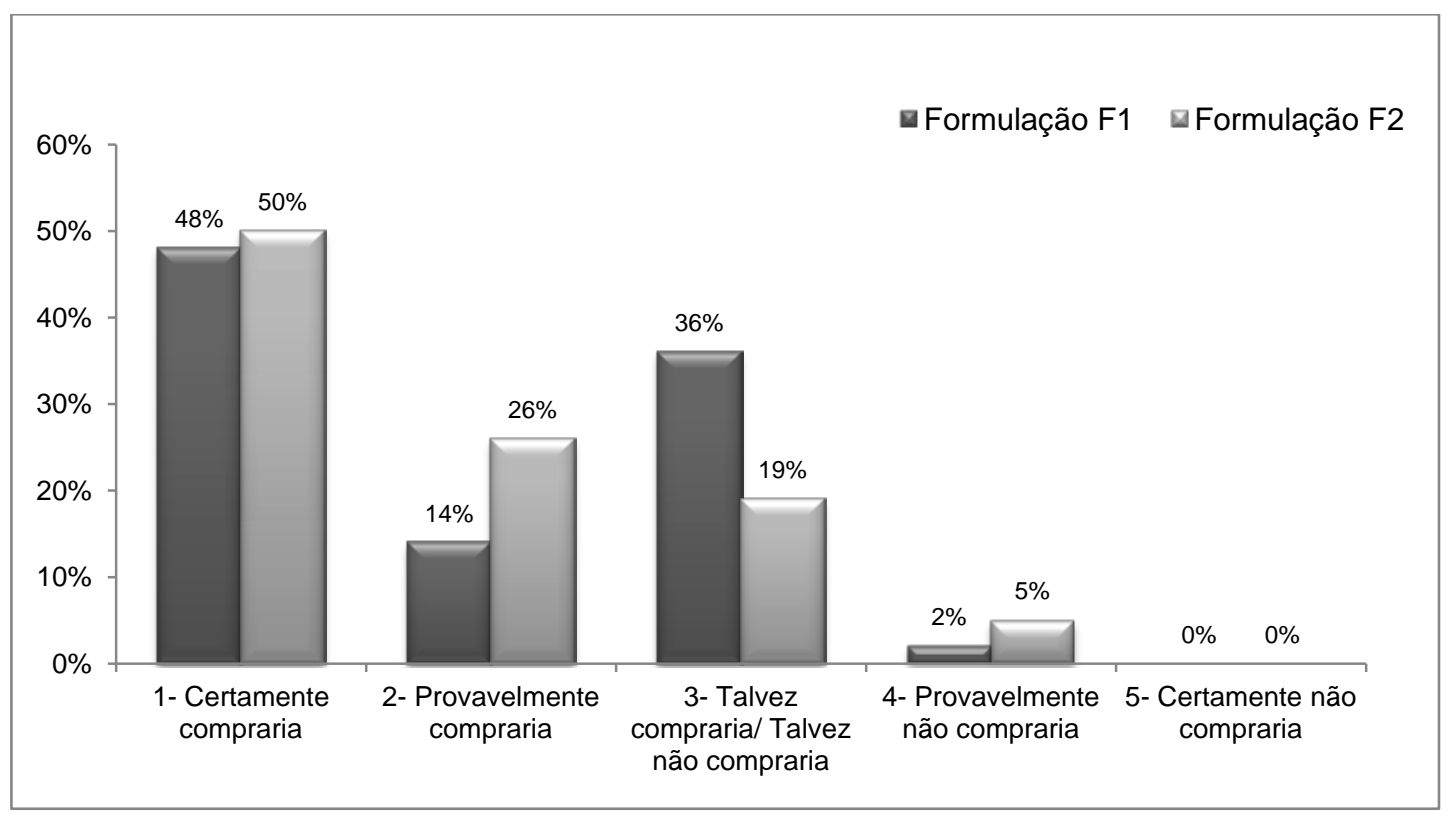

Figura 4. Intenção de compra dos biscoitos tipo cookies de amora. 
Estudos têm sido reportados na literatura com relação ao desenvolvimento de biscoitos tipo cookies a partir de farinha de vegetais ou resíduos do seu processamento, porém não com a utilização de polpa de frutas.

Pereira et al. (2019) avaliaram os teores de compostos fenólicos e os efeitos tecnológicos da substituição parcial da farinha refinada de trigo por farinha integral e farinha de amora-preta em biscoitos. Os autores observaram um aumento de $80 \% \mathrm{e}$ $2778 \%$ nos teores de fenólicos totais e antocianinas, respectivamente, comparado à formulação controle.

Alves et al. (2012) produziram cookies a partir de farinha da semente de goiaba com a substituição de $50 \%$ da quantidade de farinha de trigo. Após a elaboração do produto, realizou-se o teste de aceitabilidade com 51 consumidores, utilizando-se a escala de atitude de sete pontos, em que 7 representava a nota máxima "comeria sempre que tivesse oportunidade" e 1 representava a nota mínima "só comeria se fosse forçado(a)". A média de aceitação do cookie de farinha da semente de goiaba foi de 6,03 pontos, correspondendo à faixa compreendida entre as notas "comeria sempre que tivesse oportunidade" e "comeria frequentemente". Verificou-se, portanto, que o cookie de farinha da semente de goiaba obteve uma boa aceitação pelos consumidores.

Santos et al. (2008) avaliaram sensorialmente duas formulações de biscoitos elaborados com resíduo obtido do processamento de polpa de amora-preta (Rubus sp.). A formulação 1 apresentava $75 \%$ de farinha de trigo e $25 \%$ de resíduo de polpa de amora-preta e a formulação 2 apresentava 50\% de farinha de trigo e $50 \%$ de resíduo de polpa de amora-preta. A avaliação sensorial dos biscoitos foi realizada, com 90 avaliadores não treinados, com idades de 19 a 50 anos, por meio do teste de aceitação, utilizando-se escala hedônica estruturada de 9 pontos e foi solicitado para registrar a expressão que melhor represente sua aceitação quanto aos atributos cor, textura, aroma e sabor, cujos extremos corresponderam a "9- gostei muitíssimo" e "1desgostei muitíssimo". Os biscoitos elaborados com $25 \%$ de resíduo de polpa de amora-preta obtiveram maior aceitação para sabor, aroma e textura do que aquele formulado com $50 \%$ do resíduo. Ambos foram igualmente aceitos em relação à cor, atributo que apresentou menor aceitabilidade.

\section{Conclusão}

Sensorialmente, os biscoitos apresentaram diferenças entre si. Com relação ao teste pareado de preferência, o biscoito formulado com $12 \%$ de polpa apresentou maior preferência (67\%) quando comprado ao biscoito formulado com $7 \%$ de polpa (33\%). As formulações apresentaram índice de aceitabilidade superior a $70 \%$, indicando 0 produto como aceito. Quando avaliada a intenção de compra, foi observado que a maioria dos avaliadores certamente comprariam os biscoitos, de ambas as formulações.

\section{Referências}

ALVES, A. M. P. et al. Elaboração e avaliação sensorial de cookie de farinha da semente de goiaba. In: VII CONNEPI, Congresso Norte e Nordeste de Pesquisa e Inovação, Palmas - Tocantins, 2012. Disponível em: http://propi.ifto.edu.br/ocs/index.php/connepi/vii/paper/viewFile/1413/2854. Acesso em: 15 fev. 2016.

ANTUNES, L. E. C. Amora-preta: nova opção de cultivo no Brasil. Ciência Rural, v. 32, n. 1, p. 151-158, 2002. http://dx.doi.org/10.1590/S0103-84782002000100026. 
ANTUNES, L. E. C. et al. Produção de Amoreira-preta no Brasil. Revista Brasileira de Fruticultura, v.36, n.1, p.100-111, 2014. Disponível em: http://www.alice.cnptia.embrapa.br/alice/handle/doc/993253. Acesso em: 26 dez. 2020.

DUTCOSKY, S. D. Análise Sensorial de Alimentos. $5^{a}$ edição revisada e ampliada. Curitiba: PUCPress, 2019.

FASOLIN, L. H. et al. Biscoitos produzidos com farinha de banana: avaliações química, física e sensorial. Ciência e Tecnologia de Alimentos, v. 27, n.3, p. 524529, 2007. http://dx.doi.org/10.1590/S0101-20612007000300016.

GAZOLA, M. B. Caracterização de polpas e bebidas à base de extrato hidrossolúvel de soja, amora, pitanga e mirtilo - Análises reológicas, fitoquímicas, físico-químicas, microbiológicas e sensoriais. 2014. Dissertação (Mestrado em Tecnologia de Processos Químicos e Bioquímicos) - Universidade Tecnológica Federal do Paraná, Pato Branco, 2014.

IMRAN, M. et al. Chemical composition and antioxidant activity of certain Morus species. Journal of Zhejiang University-SCIENCE B (Biomedicine \& $\begin{array}{llllll}\text { Biotechnology), } & \text { v. } 11, \quad \text { n. } 12, & \text { p. } & 973-980,\end{array}$ http://dx.doi.org/10.1631/jzus.B1000173.

JACQUES, A. C.; ZAMBIAZI, R. C. Fitoquímicos em amora-preta (Rubus spp). Semina: Ciências Agrárias, v. 32, n. 1, p. 245-260, 2011. http://dx.doi.org/10.5433/1679-0359.2011v32n1p245.

MOTA, R. V. da. Caracterização física e química de geleia de amora-preta. Ciência e Tecnologia de Alimentos, v. 26, n. 3, p. 539-543, 2006. http://dx.doi.org/10.1590/S0101-20612006000300009.

NEWTRADE. Indústrias de biscoitos, massas e pães \& bolos alcançam faturamento de $\mathrm{R} \$ 36,7$ bilhões em 2019. Disponível em: https://newtrade.com.br/industria/industrias-de-biscoitos-massas-e-paes-bolosalcancam-faturamento-de-r-367-bilhoes-em-2019/. Acesso em: 22 nov. 2020.

O'MAHONY, M. Sensory evaluation of food: statistical methods and procedures. v.16, New York: Marcel Dekker, Inc.. 1986.

PEREIRA, A. P. A. et al. Blackberries (Rubus sp.) and whole grain wheat flour in cookies: evaluation of phenolic compounds and technological properties. Journal of Food Science and Technology, v. 56, n.3, p. 1445-1453, 2019. http://dx.doi.org/10.1007/s13197-019-03628-6.

SANTOS, V. da S. et al. Avaliação sensorial de biscoitos elaborados com resíduo de polpa de amora-preta (Rubus spp.). In: XVII CONGRESSO DE INICIAÇÃO CIENTÍFICO DA UFPEL, 2008, Pelotas. Anais [...]. Pelotas: UFPel, 2008. p. 01-05

STATSOFT. Statistica for Windows. Tulsa: Stasoft, 2007.

STRIK, B. C. et al. Worldwide Blackberry Production. HortTechnology, v.17, n.2, p.205-213, 2007. http://dx.doi.org/10.21273/HORTTECH.17.2.205.

TACO. Tabela Brasileira de Composição de Alimentos. $4^{a}$ edição revisada e ampliada. Campinas: NEPA-UNICAMP, 2011. 161 p. Disponível em: 
http://www.unicamp.br/nepa/taco/contar/taco_4_edicao_ampliada_e_revisada.pdf?arq uivo=taco_4_versao_ampliada_e_revisada.pdf. Acesso em: 15 out. 2014.

TEIXEIRA, E.; MEINERT, E. M.; BARBETTA, P. A. Métodos sensoriais. In: Análise sensorial de Alimentos. Florianópolis: UFSC, 1987. p. 66-119.

TULLIO, L.; AYUB, R. A. Produção da amora-preta cv Tupy, em função da intensidade da poda. Semina: Ciências Agrárias, v. 34, n. 3, p. 1147-1152, 2013. http://dx.doi.org/10.5433/1679-0359.2013v34n3p1147.

\section{Agradecimentos}

Ao Instituto Federal do Paraná.

\section{Autores}

Michele Rosset ${ }^{1, \star}$, Márcia Arocha Gularte ${ }^{2}$

1. Curso de Pós-graduação Lato Sensu em Ciência dos Alimentos, Centro de Ciências Químicas, Farmacêuticas e de Alimentos, UFPel, Campus Universitário, Caixa Postal, 354, 96010-900, Pelotas, RS, Brasil. Instituto Federal do Paraná, Campus Colombo. Rua Antônio Chemin, 28, São Gabriel, 83403-515, Colombo, Paraná, Brasil.

2. Centro de Ciências Químicas, Farmacêuticas e de Alimentos, Universidade Federal de Pelotas, Campus Universitário, Caixa Postal, 354, 96010-900, Pelotas, RS, Brasil.

\footnotetext{
* Autor para correspondência: michele.rosset@ifpr.edu.br
} 